\title{
Validation of the pooled cohort risk score in an Asian population - a retrospective cohort study
}

\author{
Yook Chin Chia ${ }^{1,2^{*}}$, Hooi Min Lim ${ }^{1}$ and Siew Mooi Ching ${ }^{3,4}$
}

\begin{abstract}
Background: The Pooled Cohort Risk Equation was introduced by the American College of Cardiology (ACC) and American Heart Association (AHA) 2013 in their Blood Cholesterol Guideline to estimate the 10-year atherosclerotic cardiovascular disease (ASCVD) risk. However, absence of Asian ethnicity in the contemporary cohorts and limited studies to examine the use of the risk score limit the applicability of the equation in an Asian population. This study examines the validity of the pooled cohort risk score in a primary care setting and compares the cardiovascular risk using both the pooled cohort risk score and the Framingham General Cardiovascular Disease (CVD) risk score.

Methods: This is a 10-year retrospective cohort study of randomly selected patients aged 40-79 years. Baseline demographic data, co-morbidities and cardiovascular (CV) risk parameters were captured from patient records in 1998. Pooled cohort risk score and Framingham General CVD risk score for each patient were computed. All ASCVD events (nonfatal myocardial infarction, coronary heart disease (CHD) death, fatal and nonfatal stroke) occurring from 1998-2007 were recorded.
\end{abstract}

Results: A total of 922 patients were studied. In 1998, mean age was $57.5 \pm 8.8$ years with $66.7 \%$ female. There were $47 \%$ diabetic patients and $59.9 \%$ patients receiving anti-hypertensive treatment. More than $98 \%$ of patients with pooled cohort risk score $\geq 7.5 \%$ had FRS $>10 \%$. A total of 45 CVD events occurred, 22 (7.2\%) in males and 23 (3.7\%) in females. The median pooled cohort risk score for the population was 10.1 (IQR 4.7-20.6) while the actual ASCVD events that occurred was 4.9\% (45/922). Our study showed moderate discrimination with AUC of 0.63 . There was good calibration with Hosmer-Lemeshow test $\chi 2=12.6, P=0.12$.

Conclusions: The pooled cohort risk score appears to overestimate CV risk but this apparent over-prediction could be a result of treatment. In the absence of a validated score in an untreated population, the pooled cohort risk score appears to be appropriate for use in a primary care setting.

Keywords: Pooled cohort risk score, Atherosclerotic cardiovascular disease, Validation, Asian population, Framingham risk score, Cardiovascular events, Primary care, Retrospective cohort, Malaysia

\section{Background}

The American College of Cardiology (ACC) and American Heart Association (AHA) released a new guideline on blood cholesterol management in November 2013. This guideline introduced the new pooled cohort risk equation to estimate 10-year atherosclerotic cardiovascular disease (ASCVD) risk, which includes nonfatal myocardial

\footnotetext{
* Correspondence: chiayc@um.edu.my

'Department of Primary Care Medicine, University of Malaya Primary Care Research Group (UMPCRG), Faculty of Medicine, University of Malaya, 50603 Kuala Lumpur, Malaysia

${ }^{2}$ Curtin Health Innovation Research Institute, Faculty of Health Sciences, Curtin University, GPO Box U1987, 6845 Perth, WA, Australia

Full list of author information is available at the end of the article
}

infarction (MI), coronary heart disease (CHD) death, nonfatal and fatal stroke [1]. The pooled cohort risk equation was derived from four major population-based cohort studies in the United States involving white and black Americans and this new risk tool was further validated by two external cohorts: Reasons for Geographic and Racial Differences in Stroke (REGARDS) and MultiEthnic Study of Atherosclerosis (MESA) [2,3]. This pooled cohort risk score serves as a guide to help clinician in deciding statin initiation for patients with mildly elevated $\mathrm{CV}$ risk. Statin is recommended as primary prevention for those non-diabetic patients with LDL $90-189 \mathrm{mg} / \mathrm{dl}$ and pooled cohort risk score $\geq 7.5 \%$. 
Opinions and debates have arisen since the introduction of the pooled cohort risk score. The applicability of the pooled cohort risk score is being questioned because it is perceived to overestimate $\mathrm{CV}$ risk due to the lower cut-off point of $7.5 \%$ and that more patients will need to be treated with statins if the pooled cohort risk score is applied [4-6].

Absence of Asian ethnicity in the contemporary cohorts and external cohorts limit the applicability of the pooled cohort risk score in the Asian population. Until recently very few studies examined the use of pooled cohort risk score in different populations. Hence, our aim was to validate the use of the pooled cohort risk equation in an Asian population. We also compared the CV risk of our population using both the pooled cohort risk score and the Framingham General CVD risk score.

\section{Methods}

\section{Setting}

This study is a 10-year retrospective cohort study of randomly selected patients registered with an outpatient primary care clinic of University Malaya Medical Centre (UMMC). The hospital is located in Kuala Lumpur, the capital of Malaysia. The main ethnic groups in this population are Malay, Chinese and Indian. The outpatient clinic is under the Department of Primary Care Medicine which is run by 14 family medicine specialists and 30 vocational trainees in family medicine. Ethics approval was obtained from the Ethics Committee of the institution.

\section{Study population}

There were 1536 patients in our original cohort. We excluded patients aged $<40$ or aged $>79(\mathrm{n}=83)$ as this was out of the age range of the pooled cohort risk score calculator. Out of 1453 patients, 526 (36.2\%) patients were also excluded as they did not have all the variables needed to calculate the pooled cohort risk score. Another 5 patients was excluded as we could not ascertain their CVD status by the end of 2007. Hence a total of 922 patients $(63.5 \%)$ were eligible for analysis (Figure 1). Our follow-up rate over the 10 -years was $95 \%$ (871/922) with only 51 (5\%) patients who did not come for follow up.

\section{Inclusion criteria}

Adults aged 40-79 without clinical ASCVD who were already registered in our centre in 1998.

\section{Exclusion criteria}

Patients who did not have all the variables to calculate the pooled cohort risk score at baseline were excluded.

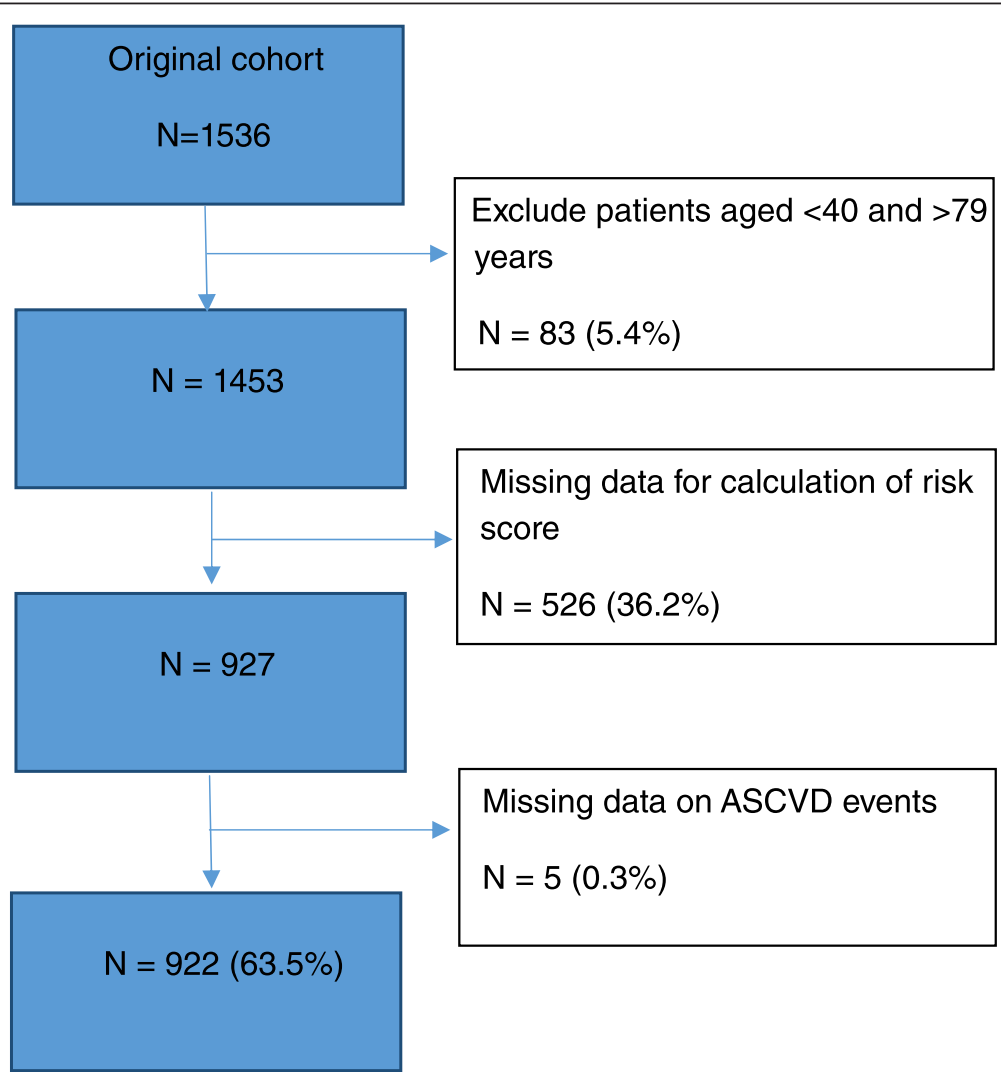

Figure 1 Flowchart of patients included in the analysis. 
We also excluded patients with missing data on the ASCVD event.

\section{Data collection}

Random numbers were generated by computer based on the patients' registration number with the clinic. Baseline data was collected in 1998 and follow-up data collected in 2007, a 10-year interval. We extracted the patients' information from their paper-based records manually. Socio-demograhic data and co-morbidities were recorded.

A pooled cohort risk score for each patient was computed using the online Pooled Cohort Risk Equation provided by the American Heart Association [7]. For the variable race, we used 'White or others' for our study population. The Framingham risk score (FRS) for 10-year risk of cardiovascular disease (CVD) was also calculated based on the Framingham General CVD risk score chart [8]. All the variables needed for calculation of both the scores are shown in Table 1. ASCVD events in the 10-year period (1998-2007) were captured. ASCVD event is defined as nonfatal myocardial infarction (MI), CHD death, nonfatal and fatal stroke [1]. ASCVD events in our cohort were based on the clinicians' diagnosis supported by the relevant investigations. For those who defaulted and did not complete

Table 1 Variables for pooled cohort risk score and Framingham general CVD risk score

\begin{tabular}{lll}
\hline & Pooled cohort risk score & $\begin{array}{l}\text { Framingham general CVD } \\
\text { risk score }\end{array}$ \\
\hline Variables & Sex & Sex \\
& Age & Age \\
& Race & - \\
& Total cholesterol $(\mathrm{mg} / \mathrm{dl})$ & Total cholesterol $(\mathrm{mg} / \mathrm{dl})$ \\
& HDL cholesterol $(\mathrm{mg} / \mathrm{dl})$ & HDL cholesterol $(\mathrm{mg} / \mathrm{dl})$ \\
& Systolic blood pressure & Systolic blood pressure \\
(mmHg) & (mmHg) \\
& Treatment for high blood & Treatment for high blood \\
pressure & pressure \\
& Diabetes & Diabetes \\
Smoker & Smoker \\
Nonfatal myocardial & Nonfatal myocardial infarction \\
infarction & \\
CHD death & CHD death \\
Nonfatal stroke & Angina \\
Fatal stroke & Cardiac failure \\
& Nonfatal stroke \\
& Fatal stroke \\
& Peripheral arterial disease \\
& &
\end{tabular}

CVD Cardiovascular Disease; HDL high density lipoprotein; CHD cardiovascular heart disease. their subsequent 10 year follow-up at our clinic $(n=31)$ we traced and examined their case records with the main hospital to determine their CVD outcome. For those patients who did not attend our clinics or hospital after being entered into our study, we called the patient or their family individually $(n=20)$ to ascertain their CVD status. We were not able to ascertain CVD outcome in only 5 patients.

Blood Pressure (BP) was measured by our attending doctor using a mercury sphygmomanometer as part of the daily routine practice. Diagnosis of hypertension is made in accordance with standard recommendations i.e. $\mathrm{BP} \geq 140 / 90 \mathrm{mmHg}$ based on at least 2 blood pressure measurements at least 2 weeks apart [9]. The use of anti-hypertensive agents was recorded as well. Diabetes mellitus was defined as documented by the attending physician or the use of hypoglycaemic agents or both. Smokers were defined if they were still smoking currently. Non-smokers were those who never smoked or currently not smoking regardless of when they had stopped smoking. Total cholesterol, LDL and HDL cholesterol were also collected. All blood tests were performed in our teaching hospital's laboratory which is certified by the Royal College of Pathologists of Australasia standards. Statin use in 1998 and 2007 was recorded.

\section{Statistical analysis}

All statistical analysis was done using the Statistical Package for Social Sciences (SPSS version 15). Categorical data are reported as proportions (percentage). Mean was used for continuous variables that were normally distributed. Median and interquartile range were used for variables that were not normally distributed.

\section{Discrimination}

Discrimination is defined as the ability of a risk prediction model to accurately rank order individuals (i.e. are individuals with higher predicted risk more likely to have events.) We used receiver operating characteristic (ROC) curve to determine the discriminative power of the pooled cohort risk score. The area under the curve (AUC), also known as c-index, was used as a measure of how well the pooled cohort risk score can discriminate. Discrimination is defined as good when the c index is closer to 1 whereas a value of 0.5 implies that the risk score tool is no better than chance [10].

\section{Calibration}

Calibration was used to assess whether the observed 10-year ASCVD events differed significantly from predicted [10]. The calibration of the pooled cohort risk score was determined using Hosmer-Lemeshow test [11]. A $\chi 2$ value of greater than 20 or a $p$ value of less than 0.05 indicates poor calibration. 


\section{Net reclassification Index (NRI)}

NRI was used to quantify improvement offered by pooled cohort risk score compared to Framingham General CVD risk score. We adopted the approach proposed by Pencina et al. for the NRI analysis [12].

\section{Results}

A total of 922 patients were eligible for this study. Table 2 shows the clinical characteristics of the study population at baseline in 1998. Overall, the mean age of the population was $57.5 \pm 8.8$ years and about two-thirds of the population was female $(66.7 \%, n=615)$. The major ethnic group was Chinese $(46.1 \%, \mathrm{n}=425)$, followed by Indian $(29.8 \%, \mathrm{n}=275)$ and Malay $(22.7 \%, \mathrm{n}=210)$. Nearly half of the patients were diabetic (47\%). $87.5 \%$ $(n=371)$ of these diabetic patients were receiving treatment with either oral hypoglycaemic agents and/or insulin. The mean systolic BP was $140.9 \pm 18.6 \mathrm{mmHg}$ and more than half of the population was treated with antihypertensive agents. Only $9.7 \%$ of the population $(n=90)$ received statin therapy in 1998 . We also compared the baseline characteristics for those who were entered into our analysis to the patients who were excluded. Basically there was no substantial difference between their baseline characteristics.

Table 2 Comparison of CV risk factors in 1998 and 2007

\begin{tabular}{|c|c|c|}
\hline Clinical characteristics & 1998 & 2007 \\
\hline Age, year (mean) & $57.5 \pm 8.8$ & $67.5 \pm 8.8$ \\
\hline Sex, female (n, \%) & $615(66.7)$ & $615(66.7)$ \\
\hline \multicolumn{3}{|l|}{ Ethnicity (n, \%) } \\
\hline - Malay & $210(22.7)$ & $210(22.7)$ \\
\hline - Chinese & $425(46.1)$ & $425(46.1)$ \\
\hline - Indian & $275(29.8)$ & $275(29.8)$ \\
\hline - Others & $12(1.4)$ & $12(1.4)$ \\
\hline Diabetes mellitus ( $\mathrm{n}, \%$ ) & $424(47.0)$ & $528(57.3)$ \\
\hline - HbA1c, \% (mean) & $7.7 \pm 1.8$ & $7.5 \pm 1.6$ \\
\hline - DM controlled with HbA1c $\leq 6.5 \%$ (n, \%) & $110(11.9)$ & $163(17.7)$ \\
\hline Systolic BP, mmHg (mean) & $140.9 \pm 18.6$ & $135.1 \pm 16.6$ \\
\hline - Use of anti-hypertensive agents ( $n, \%)$ & $552(59.9)$ & $760(82.4)$ \\
\hline - BP controlled SBP $\leq 140 \mathrm{mmHg}(\mathrm{n}, \%)$ & $568(61.6)$ & $681(73.9)$ \\
\hline - RAS blocker use (n, \%) & $66(7.2)$ & $371(40.2)$ \\
\hline Total cholesterol, mg/dl (mean) & $234.8 \pm 42.3$ & $190.9 \pm 37.2$ \\
\hline HDL cholesterol, mg/dl (mean) & $47.6 \pm 14.2$ & $49.6 \pm 12.5$ \\
\hline LDL cholesterol, mg/dl (mean) & $143.1 \pm 40.7$ & $115.5 \pm 31.6$ \\
\hline Statin use in 1998 (n, \%) & $90(9.7)$ & $587(63.7)$ \\
\hline Smoker (n, \%) & $56(6.1)$ & $56(6.1)$ \\
\hline
\end{tabular}

Mean \pm Standard deviation.

CV cardiovascular, DM diabetes mellitus, BP blood pressure, SBP systolic blood pressure, RAS renin-angiotensin system, HDL high density cholesterol, LDL low density cholesterol.
Table 2 also shows the change in CVD risk factors at the end of 10 years. The number of diabetic patients increased from $47.0 \%$ to $57.3 \%$ but $\mathrm{HbAlc}$ control improved from a mean of $7.7 \%$ to $7.5 \%$. The mean systolic blood pressure was reduced by $5.8 \mathrm{mmHg}$, from $140.9 \mathrm{mmHg}$ to $135.1 \mathrm{mmHg}$. The number of patients who had controlled BP with systolic BP $\leq 140 \mathrm{mmHg}$ increased from $61.6 \%$ to $73.9 \%$. There was an increase in the use of renin-angiotensin system (RAS) blockers from $7.2 \%$ to $40.2 \%$. The number of patients receiving statin increased significantly from $9.7 \%$ to $63.7 \%$ in 2007 . There was also improvement in the lipid profile of patients at the end of 10 years compared to baseline. Mean of total cholesterol was reduced from $234.8 \mathrm{mg} / \mathrm{dl}$ to $190.9 \mathrm{mg} / \mathrm{dl}$ while the mean HDL increased from $47.6 \mathrm{mg} / \mathrm{dl}$ to $49.6 \mathrm{mg} / \mathrm{dl}$.

Table 3 compares the 10 -year CV risk of our population at baseline using both the FRS and the pooled cohort risk score. For those with pooled cohort risk score of $7.5-9.9 \%, 98.8 \%$ of them have FRS $\geq 10 \%$. Whereas in those patients with pooled cohort risk score 10-19.9\% and $\geq 20 \%, 99.6 \%$ of them have FRS $\geq 10 \%$. Hence, we conclude that more than $98 \%$ of patients with pooled cohort risk score $\geq 7.5 \%$ have a FRS of $>10 \%$. In those with pooled cohort risk score of $<7.5 \%$, two-thirds have FRS of $>10 \%$. Only $13.4 \%(124 / 922)$ have low risk in both risk scores.

Table 4 shows the comparison of predicted and observed pooled cohort risk score in 1998 and ASCVD events in the 10-year interval from 1998 to 2007 in our primary care patients. The median pooled cohort risk score for the study population was $10.1 \%$ (IQR 4.7-20.6). The actual number of ASCVD events that occurred in the 10 years was $45(45 / 922=4.9 \%)$ while the predicted was 93. In men, their median pooled cohort risk score was $21.1 \%$ while the events that occurred was 22 (7.2\%). In women, their median pooled cohort risk score $6.7 \%$ while the event that occur was 23 (3.7\%). Similarly the events rate was twice as high in men (7.2\%) than women (3.7\%). Interestingly, we noticed that 8 (2.2\%) ASCVD events occurred in those patients with pooled cohort risk score $\leq 7.5 \%(\mathrm{~N}=367)$. We analysed the $\mathrm{CV}$ risk for this group of patients and found out that $36 \%$ had DM and $51 \%$ hypertension. Over the 10 -year period, the prevalence of DM and hypertension increased to $49 \%$ and $80.9 \%$ respectively. The statin use for this low risk group of patients was increased from $10.4 \%$ to $68.1 \%$.

The AUC for pooled cohort risk score was 0.63 showing moderate discrimination as shown in Figure 2. The calibration for pooled cohort risk score was good as the Hosmer-Lemeshow test result was $\chi 2=12.6, P=0.12$. We also calculated the Net Reclassification Index (NRI) and the NRI is $3.1 \%(\mathrm{p}=0.001)$. This indicates that the pooled cohort risk score provided $3.1 \%$ more net reclassification improvement. 
Table 3 Comparison of 10-year cardiovascular risk in 1998 between the pooled cohort risk score and Framingham general CVD risk score

\begin{tabular}{|c|c|c|c|c|c|}
\hline \multirow{4}{*}{$\begin{array}{l}\text { 10-year CVD risk (Framingham } \\
\text { general CVD risk score) }\end{array}$} & \multicolumn{5}{|c|}{ 10-year ASCVD risk (pooled cohort risk score) } \\
\hline & \multicolumn{5}{|c|}{$(\mathrm{N}=922)$} \\
\hline & $<7.5 \%$ & $7.5-9.9 \%$ & $10.0-19.9 \%$ & $\geq 20 \%$ & Total \\
\hline & $N(\%$ of total $N)$ & $N(\%$ of total $N)$ & $\mathrm{N}(\%$ of total $\mathrm{N})$ & $\mathrm{N}(\%$ of total $\mathrm{N})$ & \\
\hline$<10 \%$ & $124(34.0)$ & $1(1.2)$ & $1(0.4)$ & $1(0.4)$ & 128 \\
\hline $10-20 \%$ & $197(53.7)$ & $35(40.7)$ & $44(19.3)$ & $2(0.8)$ & 278 \\
\hline$>\mathbf{2 0} \%$ & $45(12.5)$ & $50(58.1)$ & $183(80.3)$ & $238(98.8)$ & 520 \\
\hline Total & 366 & 86 & 228 & 241 & 922 \\
\hline
\end{tabular}

ASCVD: atherosclerosis cardiovascular disease; CVD cardiovascular disease.

Table 5 shows the comparison between pooled cohort risk score and ASCVD events according to ethnicity. The pooled cohort risk score discriminates moderately well for Malay race (AUC 0.73, $\mathrm{p}=0.011$ ) but not for the Chinese and Indian.

\section{Discussion}

A very recent study validated the pooled cohort risk score in a US population and found it to work very well [2]. Our

Table 4 Comparison of predicted and observed pooled cohort risk score in 1998 and ASCVD events in a 10-year interval (1998-2007)

\begin{tabular}{|c|c|c|c|}
\hline $\begin{array}{l}\text { Pooled cohort risk } \\
\text { score in } 1998, \%\end{array}$ & Total, N & $\begin{array}{l}\text { Observed ASCVD } \\
\text { event }(n, \%)\end{array}$ & $\begin{array}{l}\text { Predicted ASCVD } \\
\text { Events (n, \%) }\end{array}$ \\
\hline \multicolumn{4}{|l|}{ All adults } \\
\hline Median score: $10.1 \%$ & 922 & $45(4.9)$ & $93(10.1)$ \\
\hline \multicolumn{4}{|l|}{ (95\% Cl 4.7-20.6) } \\
\hline$-<7.5 \%$ & 367 & $8(2.2)$ & $14(3.8)$ \\
\hline - 7.5-9.9\% & 86 & $6(7.0)$ & $7(8.4)$ \\
\hline - 10-19.9\% & 228 & $12(5.3)$ & $32(13.9)$ \\
\hline$-\geq 20 \%$ & 241 & 10(7.9) & $73(30.5)$ \\
\hline \multicolumn{4}{|l|}{ Male } \\
\hline Median score: $21.1 \%$ & 307 & $22(7.2)$ & $64(21.1)$ \\
\hline \multicolumn{4}{|l|}{ (95\% Cl 12.0-31.9) } \\
\hline$-<7.5 \%$ & 32 & 0 & $1(4.5)$ \\
\hline - $7.5-9.9 \%$ & 19 & $1(5.3)$ & $2(8.2)$ \\
\hline - 10-19.9\% & 92 & $6(6.5)$ & $13(14.3)$ \\
\hline$-\geq 20 \%$ & 164 & $15(9.1)$ & $51(31.1)$ \\
\hline \multicolumn{4}{|l|}{ Female } \\
\hline Median score: $6.7 \%$ & 615 & $23(3.7)$ & $41(6.7)$ \\
\hline \multicolumn{4}{|l|}{$(95 \% \mathrm{Cl} 3.3-13.0)$} \\
\hline$-<7.5 \%$ & 335 & $8(2.4)$ & $12(3.6)$ \\
\hline - 7.5-9.9\% & 67 & $5(7.5)$ & $6(8.4)$ \\
\hline - 10-19.9\% & 136 & $6(4.4)$ & $18(13.5)$ \\
\hline$-\geq 20 \%$ & 77 & $4(5.2)$ & $22(28.2)$ \\
\hline
\end{tabular}

$\mathrm{Cl}=$ Confidence Interval. study showed that the pooled cohort risk score has moderate discrimination and good calibration in an Asian population. One possible explanation of our finding of only moderate discrimination could be because of the high prevalence of patients with $\mathrm{CV}$ risk factors (i.e. the high prevalence of diabetes and hypertension seen) and therefore a clustering of patients with higher risk and fewer patients with lower risk. Hence in a general population of subjects with a wider range of CV risk, this risk prediction model may give a better discrimination.

However, the number of observed events was fewer than predicted. This apparent over-estimation could be because of treatment which would result in a reduction of ASCVD events. As seen in our study, the number of patients receiving statin therapy increased from 9.7\% $(\mathrm{n}=90)$ to $63.7 \%(\mathrm{n}=587)$ over the 10-year period. Besides the increase in statin use other $\mathrm{CV}$ risk factors were also improved where the mean systolic blood pressure, mean

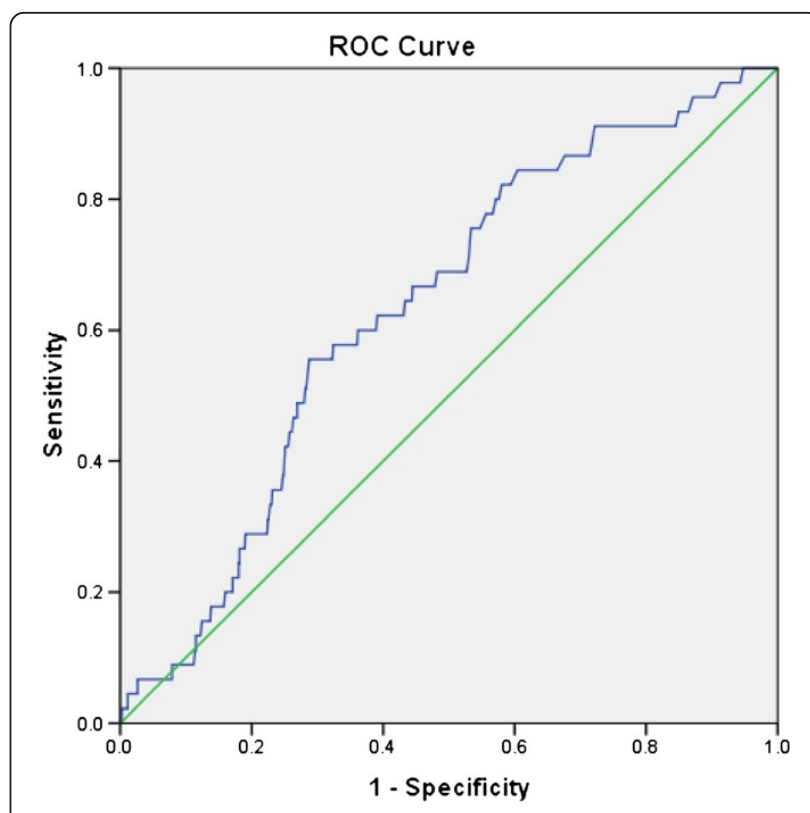

Figure 2 ROC and AUC for pooled cohort risk score. 
Table 5 Comparison pooled cohort risk score and ASCVD events according to ethnicity

\begin{tabular}{|c|c|c|c|c|c|}
\hline & \multirow[t]{3}{*}{ Pooled cohort risk score (\%) } & \multicolumn{2}{|c|}{ ASCVD event } & \multirow[t]{3}{*}{ AUC $(95 \% \mathrm{Cl})$} & \multirow[t]{3}{*}{$p$-value } \\
\hline & & Observed & Predicted & & \\
\hline & & $\mathrm{N}(\%)$ & $\mathrm{N}$ & & \\
\hline Overall $(N=922)$ & 10.1 & $45(4.9)$ & 93 & $0.632(0.557,0.70)$ & 0.003 \\
\hline Malay $(\mathrm{N}=210)$ & 7.9 & $10(4.8)$ & 17 & $0.737(0.641,0.834)$ & 0.011 \\
\hline Chinese $(N=425)$ & 10.8 & $21(4.9)$ & 46 & $0.625(0.512,0.737)$ & 0.054 \\
\hline Indian $(N=275)$ & 10.0 & $14(5.1)$ & 28 & $0.576(0.417,0.736)$ & 0.335 \\
\hline
\end{tabular}

$\mathrm{AUC}=$ Area under curve.

HbA1c, total and LDL-cholesterol were all reduced over the 10-year period. Control rate for blood pressure and diabetes as well as use of RAS blockers also increased [13]. Studies have shown that a reduction of $10 \mathrm{mmHg}$ of blood pressure can result in a reduction of $25 \%$ of $\mathrm{CHD}, 45 \%$ of stroke and 55\% of heart failure [14,15]. Furthermore, a 1\% decrease in HbA1c level can lead to a reduction of fatal and non-fatal MI by $14 \%$, peripheral vascular disease by $43 \%$ and heart failure by $16 \%$ [16]. For LDL cholesterol level, every $38 \mathrm{mg} / \mathrm{dl}$ of LDL reduction associated with $20 \%$ reduction of CVD events [17]. In view of the treatment given and the control rates achieved, there would be substantial improvement of all the CV risk factors in our study population over the 10-year period, leading to significant reduction of ASCVD events.

One of the reasons the pooled cohort risk score was introduced is because it is derived from a more diverse population when compared to FRS which is based on a more homogenous cohort. While the pooled cohort risk score has not been widely validated yet, the Framingham General CVD risk score has been well studied even outside the US [18-23]. However, NRI of $3.1 \%$ in our study showed there was no substantial improvement of the pooled cohort risk score over the FRS suggesting that both risk scores are equivalent.

There is general concern that using the lower threshold of $7.5 \%$ based on the pooled cohort risk score to determine the need for statin therapy will mean that more patients will be treated with statin [10]. However some reports suggest otherwise [24,25]. Furthermore, our study showed that in those with pooled cohort risk score of 7.59.9\%, almost all had a FRS of $>10 \%$ suggesting that this new AHA/ACC recommendation may be appropriate.

The proportion of patients with low risk in our study is small because our cohort is made up of actual patients whose $\mathrm{CV}$ risks are expected to be higher and hence there will be fewer people with low risk in our cohort. However, the individuals that were identified as low risk by pooled cohort risk score did actually have ASCVD events. This group of low risk patients was relatively younger with mean age of 50.8 years. Even though their risks were calculated to be low at baseline, some of them did have diabetes (32.7\%) and 51\% have hypertension. Furthermore these patients' risk increased over the 10 -year period, with aging and with more of them developing diabetes (49\%) and hypertension (80.6\%). Statin use also increased amongst these low risk patients suggesting that they developed dyslipidaemia along the way thus increasing their risk for $\mathrm{CV}$ events.

Interestingly, in those patients with pooled cohort risk score $<7.5 \%$, about two-thirds of these patients have a FRS of $>10 \%$. This discrepancy could be because the FRS predicts not just only fatal and non fatal stroke, nonfatal MI and CHD death used in the pooled cohort risk score, but also include angina, cardiac failure and peripheral arterial disease. Hence the FRS score would appear magnified when compared to pooled cohort risk score.

\section{Strengths and limitations}

Our long study period allowed us to obtain data on ASCVD events over 10 years. This is in accordance with the pooled cohort risk equation which was designed to estimate a 10-year ASCVD risk. Our study was conducted in a primary care setting where most patients have not had any ASCVD events yet. And this is the group of patients who will be the main target for risk stratification so that primary prevention can be initiated appropriately. Besides that, we were able to compare the characteristics of those with missing data and those included in the analysis and found no clinical differences between them, suggesting there was no substantial bias.

As this is a retrospective cohort study, recall bias in the actual CV events may occur especially for those patients who defaulted follow-up in our centre and therefore without proper documentation of events.

\section{Conclusion}

In our study, when compared to using the FRS, the pooled cohort risk score using a lower threshold of 7.5\% risk does not appear to overestimate CV risk. However the pooled cohort risk score appears to overestimate absolute $\mathrm{CV}$ risk as the observed events are less than 
predicted. This apparent over-prediction could be the result of treatment. Hence, in the absence of validation of the pooled cohort risk score in an untreated population, the pooled cohort risk score is appropriate for use in a primary care setting.

\section{Abbreviations}

ASCVD: Atherosclerosis cardiovascular disease; ACC/AHA: American College of cardiology and American Heart Association; CV: Cardiovascular; HDL: High density lipoprotein; LDL: Low density lipoprotein; DM: Diabetes mellitus; BP: Blood pressure; RAS: Renin-angiotensin system; FRS: Framingham risk score risk; MI: Myocardial infarction; CHD: Coronary heart disease.

\section{Competing interests}

The authors declare that they have no competing interests.

\section{Authors' contributions}

CYC contributed to the conceptualization of the paper, data entry and writing of the manuscript while LHM and CSM contributed to data analysis and writing of the manuscript. CYC is the corresponding author. All the authors read and approved the final manuscript.

\section{Acknowledgements}

The author would like to acknowledge University Malaya for providing the research grant (UMRG 116/09HTM) and Department of Primary Care at the University of Malaya for providing the support during the data collection. We also thank Associate Professor Karuthan Chinna from the Department of Social and Preventive Medicine, University of Malaya.

\section{Author details}

'Department of Primary Care Medicine, University of Malaya Primary Care Research Group (UMPCRG), Faculty of Medicine, University of Malaya, 50603 Kuala Lumpur, Malaysia. ${ }^{2}$ Curtin Health Innovation Research Institute, Faculty of Health Sciences, Curtin University, GPO Box U1987, 6845 Perth, WA Australia. ${ }^{3}$ Department of Family Medicine, Faculty of Medicine and Health Sciences, Universiti Putra Malaysia, 43400 Serdang, Malaysia. ${ }^{4}$ Department of Gerontology, Universiti Putra Malaysia, 43400 Serdang, Malaysia.

Received: 28 July 2014 Accepted: 12 November 2014

Published: 20 November 2014

\section{References}

1. Stone NJ, Robinson JG, Lichtenstein AH, Bairey Merz CN, Blum CB, Eckel RH, Goldberg AC, Gordon D, Levy D, Lloyd-Jones DM, McBride P, Schwartz JS, Shero ST, Smith SC Jr, Watson K, Wilson PW: 2013 ACC/AHA guideline on the treatment of blood cholesterol to reduce atherosclerotic cardiovascular risk in adults: a report of the American college of cardiology/American heart association task force on practice guidelines. J Am Coll Cardiol 2013, 129(25):S1-S45.

2. Muntner P, Colantonio LD, Cushman M, Goff DC Jr, Howard G, Howard VJ, Kissela B, Levitan EB, Lloyd-Jones DM, Safford MM: Validation of the atherosclerotic cardiovascular disease pooled cohort risk equations. JAMA 2014, 311(14):1406-1415.

3. Bild DE, Bluemke DA, Burke GL, Detrano R, Diez Roux AV, Folsom AR, Greenland P, Jacobs DR Jr, Kronmal R, Liu K, Nelson JC, O'Leary D, Saad MF, Shea S, Szklo M, Tracy RP: Multi-ethnic study of atherosclerosis: objectives and design. Am J Epidemiol 2002, 156(9):871-881.

4. Pencina MJ, Navar-Boggan AM, D'Agostino RB Sr, Williams K, Neely B, Sniderman AD, Peterson ED: Application of new cholesterol guidelines to a population-based sample. NEJM 2014, 370(15):1422-1431.

5. Kavousi M, Leening MJG, Nanchen D, Greenland P, Graham IM, Steyerberg EW, Ikram MA, Stricker BH, Hofman A, Franco OH: Comparison of application of the ACC/AHA guidelines, adult treatment panel III guidelines, and europeon society of cardiology guidelines for cardiovascular disease prevention in a European cohort. JAMA 2014, 311(14):1416-1423.

6. Ioannidis JP: More than a million people taking statins? Potential implications of the new cardiovascular guidelines. JAMA 2014, 311(5):463-464.

7. Goff DC Jr, Lloyd-Jones DM, Bennett G, Coady S, D'Agostino RB, Gibbons R, Greenland P, Lackland DT, Levy D, O'Donnell CJ, Robinson JG, Schwartz JS, Shero ST, Smith SC Jr, Sorlie P, Stone NJ, Wilson PW, Jordan HS, Nevo L,
Wnek J, Anderson JL, Halperin JL, Albert NM, Bozkurt B, Brindis RG, Curtis LH, DeMets D, Hochman JS, Kovacs RJ, Ohman EM, et al: ACC/ AHA guideline on the assessment of cardiovascular risk: a report of the American college of cardiology/American heart association task force on practice guidelines [published online November 12, 2013]. Circulation 2014, 129(25 Suppl 2):S49-S73. doi:10.1161/01.cir.0000437741.48606.98. published online November 12, 2013.

8. D'Agostino RB, Vasan RS, Pencina MJ, Wolf PA, Cobain M, Massaro JM, Kannel WB: General cardiovascular risk profile for use in primary care the Framingham Heart Study. Circulation 2008, 117(6):743-753.

9. Chobanian AV, Bakris GL, Black HR, Cushman WC, Green LA, Izzo JL, Jones DW, Materson BJ, Oparil S, Wright JT Jr, Roccella EJ: Seventh report of the joint national committee on prevention, detection, and treatment of high blood pressure. Hypertension 2003, 42(6):1206-1252.

10. Vergouwe Y, Steyerberg EW, Eijkemans MJ, Habbema JD: Validity of prognostic models: when is a model clinically useful? Semin Urol Oncol 2002, 20(2):96-107.

11. Lemeshow S, Hosmer DWJ: A review of goodness of fit statistics for use in the development of logistic regression models. Am J Epidemiol 1982, 115(1):92-106

12. Pencina MJ, D' Agostina RB Sr, Steyerberg EW: Extension of net reclassification improvement calculations to measure usefulness of new biomarkers. Stat Med 2011, 30(1):11-21

13. Chin CY, Mooi VLKCS: Antihypertensive prescribing pattern and blood pressure control among hypertensive patients over a ten year period in a primary care setting in Malaysia. Life Science Journal 2013, 10(1):2031-2035.

14. MacMohan SW, Cutler JA, Furberg CD, Payne GH: The effect of drug treatment for hypertension on morbidity and mortality from cardiovascular disease: a review of randomized controlled trials. Prog Cardiovasc Dis 1986, 29(3 Suppl 1):99-118.

15. Mancia G: Blood pressure reduction and cardiovascular outcomes: past, present, and future. Am J Cardiol 2007, 100(3a):3j-9j.

16. Yu PC, Bosnyak Z, Ceriello A: The importance of glycated haemoglobin $(\mathrm{HbA}(1 \mathrm{c}))$ and postprandial glucose (PPG) control on cardiovascular outcomes in patients with type 2 diabetes. Diabetes Res Clin Pract 2010, 89(1):1-9.

17. Stein EA, Raal FJ: Targeting LDL: is lower better and is it safe? Best Pract Res Clin Endocrinol Metab 2014, 28(3):309-324.

18. Chia Y: Review of tools of cardiovascular disease risk stratification: interpretation, customisation and application in clinical practice. Singapore Med J 2011, 52(2):116-123.

19. Liu J, Hong Y, D'Agostino RB Sr, Wu Z, Wang W, Sun J, Wilson PW, Kannel WB, Zhao D: Predictive value for the Chinese population of the Framingham CHD risk assessment tool compared with the Chinese multi-provincial cohort study. JAMA 2004, 291(21):2591-2599.

20. Laurier D, Chau NP, Cazelles B, Segond P: Estimation of CHD risk in a French working population using a modified Framingham model. J Clin Epidemiol 1994, 47(12):1353-1364.

21. Brindle $P$, Jonathan $E$, Lampe $F$, Walker $M$, Whincup $P$, Fahey $T$, Ebrahim $S$ : Predictive accuracy of the Framingham coronary risk score in British men: prospective cohort study. BMJ 2003, 327(7426):1267.

22. Menotti A, Lanti M, Puddu P, Kromhout D: Coronary heart disease incidence in northern and southern European populations: a reanalysis of the seven countries study for a European coronary risk chart. Heart 2000 84(3):238-244.

23. Chin CY, Pengal S: Cardiovascular disease risk in a semirural community in Malaysia. Asia Pac J Public Health 2009, 21(4):410-420.

24. Chia YC, Lim HM, Ching SM: Does use of pooled cohort risk score overestimate the use of statin?: A retrospective cohort study in a primary care setting. BMC Fam Pract 2014, 15(1):172.

25. Johansen ME, Green LA, Sen A, Kircher S, Richardson CR: Cardiovascular risk and statin use in the United States. Ann Fam Med 2014, 12(3):215-223.

doi:10.1186/1471-2261-14-163

Cite this article as: Chia et al:: Validation of the pooled cohort risk score in an Asian population - a retrospective cohort study. BMC Cardiovascular Disorders 2014 14:163. 